Meta

Journal des traducteurs

Translators' Journal

\title{
The Strategic Dimension of Interpreting
}

\section{Kurt Kohn et Sylvia Kalina}

Volume 41, numéro 1, mars 1996

Le(s) processus de traduction / Translation Process(es)

URI : https://id.erudit.org/iderudit/003333ar

DOI : https://doi.org/10.7202/003333ar

Aller au sommaire du numéro

Éditeur(s)

Les Presses de l'Université de Montréal

ISSN

0026-0452 (imprimé)

1492-1421 (numérique)

Découvrir la revue

Citer cet article

Kohn, K. \& Kalina, S. (1996). The Strategic Dimension of Interpreting. Meta, 41(1), 118-138. https://doi.org/10.7202/003333ar
Résumé de l'article

Les auteurs analysent l'interprétation consécutive et simultanée du point de vue de la stratégie. Un concept de modelage mental basé sur le discours sert de fondement à la description du processus cognitif/linguistique et des stratégies sous-tendant la compréhension et la production en interprétation.
Ce document est protégé par la loi sur le droit d'auteur. L'utilisation des services d’Érudit (y compris la reproduction) est assujettie à sa politique d'utilisation que vous pouvez consulter en ligne.

https://apropos.erudit.org/fr/usagers/politique-dutilisation/ 


\title{
THE STRATEGIC DIMENSION OF INTERPRETING
}

\author{
KURT KOHN AND SYLVIA KaLINA \\ Tübingen University and Heidelberg University, Germany
}

\begin{abstract}
Résumé
Les auteurs analysent l'interprétation consécutive et simultanée du point de vue de la stratégie. Un concept de modelage mental basé sur le discours sert de fondement à la description du processus cognitifllinguistique et des stratégies sous-tendant la compréhension et la production en interprétation.
\end{abstract}

\begin{abstract}
This article analyses consecutive and simultaneous interpreting from a strategic point of view. A concept of discourse-based mental modelling serves as a basis to describe the cognitive-linguistic processes and strategies underlying comprehension and production in interpreted bilingual communication. By contrast with processing in the monolingual context, the interpreting process is characterised by adverse conditions including above all the lack of semantic autonomy and the continuing presence of elements of the source language during different stages of processing. The strategies interpreters use will therefore necessarily differ from those used in monolingual communication and will be adapted to the specific requirements of the interpreting process. Characteristic difficulties of interpreting and corresponding strategic processes are discussed with reference to the communicative transfer relation between source and target discourse, the sequential organisation of source discourse comprehension and target discourse production in consecutive interpreting, the parallel organisation of source discourse comprehension and target discourse production in simultaneous interpreting, and the complexity of content andlor linguistic representation of the source discourse. In an empirical analysis, a bit of simultaneous discourse is studied along with introspective data on the processes at work during production. The introspective data was obtained by means of a retrospective thinking-aloud protocol. Product-related and process-related data indicate that the strategies discussed are used in real-life interpreting situations.
\end{abstract}

\section{BACKGROUND}

Interpreting is a special type of communicative interaction which takes place when members of different language communities engage in cross-language/culture communication, using interpreters as interlingual mediators. The interpreter listens to the speaker's source discourse and produces a corresponding target discourse which will enable the target discourse audience to understand what the speaker meant. There are many ways in which this can be done, among them the traditional forms of community interpreting, liaison interpreting, dialogue interpreting and court interpreting, but also full consecutive interpreting, whispering and simultaneous and even such new forms as TV and satellite interpreting. This contribution deals with the two classical types of professional conference interpreting - consecutive and simultaneous interpreting.

In consecutive interpreting, interpreters provide a target language version after having listened to the entire source discourse or segments of approximately 3 and 12 minutes in length. They may base their rendering entirely on their memory although this is in practice rarely the case, as memorising capacity is finite and after a few rounds fatigue 
will force them to resort to strategies that will relieve the burden on their memory. These normally take the form of notes, with highly individualised note-taking systems applied by different interpreters, depending on personal preference, note-taking methods individually developed, familiarity with given subject, the languages in question, memory capacity, etc. (cf. Rozan 1973; Seleskovitch 1975; Matyssek 1989).

In simultaneous interpreting, the interpreter renders a target language version as the source discourse is being produced. The time lag between a stretch of source discourse and the target language rendering of it may range from a few words to several sentences and will depend on such factors as language pair, processing direction (structurally similar or structurally dissimilar languages), cognitive processing load, memory capacity, fatigue and interpreting strategy. Compared to consecutive interpreting, the rendering in the target language tends to be more surface-oriented, sometimes even word for word; it also tends to be more deficient as far as grammatical structure is concerned and less fluent as regards presentational aspects. On the other hand, the audience's tolerance of deficiencies in simultaneous interpreting is higher, owing to the fact that the target language listeners cannot turn off the original and are thus slightly distracted from listening to the interpreted version. Moreover, listeners are generally aware of at least some of the difficulties and complexities of interpreting processes, or are made aware of them by the presentation of the target language text.

Interpreting is a communicative activity which has been practised since very ancient times. Initially, those engaging in it had no special training. However, with professional standards rising and the technical facilities available becoming ever more sophisticated, it has now developed into a specialist activity. Today the standards achieved by professional interpreters are not usually attainable by untrained bilingual speakers, and hence special training is generally required. ${ }^{1}$

At the same time, however, it is important to see that relevant aspects of interpretation competence are closely related to and develop on the basis of a language and communication competence that human beings acquire as the result of cognitive maturation and first-language development; this competence is reinforced and strengthened with each additional language learnt. This is where the possibilities, problems and limitations of interpreting - and indeed of translating in general - all have their natural roots. Thus, understanding interpreting means first of all understanding the production and reception processes of monolingual communication. It is against the background of the potential of monolingual communicative processing that the conditions and strategic nature of interpreting need to be analysed.

Studies in interpreting have always been closely related to an underlying model of language and language processing. Relevant stages in the overall development are the following:

- The "semantic" approach by Seleskovitch $(1975,1976,1978)$ is tailored to consecutive interpreting and assumes that solely utterance meaning or sense understood in a given situation and context is the basis for interpreting and that sense is languageindependent. ${ }^{2}$ Information completely understood can easily be memorised, and rendering it in another language is not regarded as a problem as long as the target language is mastered. Observations of how interpreting works are expected to provide insights into the workings of language in general.

- Lederer $(1980,1985)$ has extended the model to simultaneous interpreting, taking into account units of meaning and top-down processes. She draws a distinction between linguistic meaning and sense and defines different strategic operations which may be linguistically or semantically determined. 
- The "coding" approach by Kirchhoff $(1976 \mathbf{a}, \mathbf{b})$ offers a model of language processing based on information theory; it stipulates a sender and his message in the source language code being decoded by the interpreter and subsequently recoded in target language code for the receiver. The model describes planning of production and its concomitant problems in the interpreting process, phase-shifting between source discourse and target discourse, problems such as information density, rate of presentation; it also lists a number of strategies of special importance in simultaneous interpreting (such as segmenting, anticipating, timing of production, generalising, etc.).

- In the early serial psycholinguistic approaches by Gerver (1975) and Moser (1978) interpreting is analysed on the basis of "flow chart" models of language processing (cf. also Massaro 1978).

- According to the "efforts model" by Gile (1991) total capacity has to be shared strategically between the listening, memorising and production effort, with consequences for the other components if more capacity is needed for any one of them.

- The dynamic psycholinguistic approaches by Stenzl (1989) Mackintosh (1985), Kurz $(1989,1992)$ Kalina $(1991,1992)$ and Pöchhacker $(1991,1993)$ are based on relevant findings of cognitive psychology and propose a model of interpreting as an integrated ensemble of strategic bottom up/top down processes.

While research on interpreting - in striking contrast to translation studies - has traditionally placed the emphasis on the strategic processes interpreters resort to when trying to cope with the specific conditions and requirements of interpreting, it was only in the eighties that appropriate linguistic models of discourse processing as a strategically controlled linguistic activity became available ( $c f$. de Beaugrande and Dressler 1980; Brown and Yule 1983; van Dijk and Kintsch 1983). This perspective opened up a considerable potential for a better understanding of how interpreting processes work - always provided that empirical investigations to this end make use of the appropriate instruments of data collection and analysis. In this connection, corpus-based and experimental studies will be of particular relevance, involving analytical but also introspective or retrospective methods familiar from research on language acquisition and translation ( $c f$. Krings 1986; Færch and Kasper 1987).

The following model of monolingual communication is designed to provide the basis for our strategy-based psycholinguistic model of interpreting.

\section{DISCOURSE-BASED MENTAL MODELLING}

Our approach to interpreting is based on a mental-modelling view of communication and interpreting/translation. According to this view, the ability of human beings to perceive/experience the "real" world and/or imagine a fictitious world is a complex cognitive affair involving an integrated set of interacting processes whose combined force is geared towards a cognitive modelling of the world. People are able to experience (and/or imagine) the world only insofar as they are able to actively and creatively model it on the basis of input data ('bottom up') and available world knowledge and beliefs ('top down'); and the range and limitations of this modelling process define the range and limitations of their world experience (and/or world imagination). Without mental modelling the perception/experience (and/or imagination) of the world would not be possible ( $c f$. Brown and Yule 1983; Jackendoff 1983; Johnson-Laird 1981, 1983).

By the same token, communication about the world presupposes mental modelling. Our ability to talk about the world we experience (or about the world we imagine) beyond pointing, acting or showing pictures - is the ability to use (written or spoken) discourse as a rather complex cognitive-linguistic device designed to evoke, support and 
shape processes of mental-world modelling by remote linguistic control. "A major function of language is to enable one person to have another's experience of the world by proxy: instead of a direct apprehension of a state of affairs, the listener constructs a model of them based on a speaker's remarks" (Johnson-Laird 1981: 139).

Language can only be used successfully for the purpose of (communicative) discourse-based mental modelling because of a specific integration of world knowledge and linguistic knowledge. While the former provides, as it were, the modelling clay, the latter supplies the modelling tools. Lexemes, phrases, grammatical structures, or intonation contours are tools designed for the processing of world knowledge with the aim of creating and using cognitive worlds for the purpose of discourse-based communication. Here, four cognitive-linguistic functions of language (in discourse) appear to be of particular importance:

- the referential activation of cognitive world knowledge, in particular by means of lexemes and the various meaning relations - denotation, sense, frame - they engage in;

- the propositional construction of a (new) mental world on the basis of activated (old) world knowledge and appropriate integration devices such as grammatical structures, lexical cohesion, inferencing;

- the illocutionary orientation of a mental world as, e.g., a fictitious world, a description of world experience, a tool for eliciting world information (question), or a blue print for changing the "real" world (request);

- the perlocutionary reaction - e.g., joy, fear, belief, trust - of the discourse partners involved, as the result of specific thematic, situational or linguistic characteristics of the discourse event.

In the following we will use the term discourse-based mental world modelling to refer to this complex ensemble of cognitive-linguistic processes intended to bring about communication by means of the integration of referential activation, propositional construction, illocutionary orientation and perlocutionary reaction.

Linguistic knowledge is knowledge about the linguistic means of expression that can be used for the referential, propositional, illocutionary and perlocutionary processing of world knowledge in discourse-based mental modelling. Speakers/listeners make use of this knowledge with intuitive and creative expertise.

It is important to note, however, that successful discourse-based mental modelling does not depend on linguistic knowledge alone. Both in production and in comprehension, discourse processing relies on a diversified knowledge base including knowledge about linguistic means of expression and discourse conventions, general world and/or specialised-subject knowledge, knowledge about the communicative situation in which the discourse is embedded, mental modelling on the basis of previous discourse, and procedural knowledge relating to, e.g., strategic principles such as the co-operative principle (Grice 1975: 45), the given/new contract (Clark and Haviland 1977), or the principles of local interpretation and analogy (Brown and Yule 1983: 58ff.) (cf. figure 1). 
LINGUISTIC KNOWLEDGE

- means of expression

- discourse conventions

PREvious discourse
WORLD/SITUATION KNOWLEDGE categories/frames episodes

\section{DISCOURSE}

Procedural KNOWLEDGE STRATEGIC PRINCIPLES

MENTAL MODELLING

- referential activation

- propositional construction

- illocutionary orientation

- perlocutionary reaction

Figure 1: Components of discourse-based mental modelling

In this connection, the distinction between the bottom-up and top-down dimension of cognitive (discourse) processing should be kept in mind. While bottom-up processing works from the physical to the mental level, from input data to interpretations, top-down processing starts from expectations and proceeds to generate cognitive projections of interpretations. The difference in processing difficulty, for instance, between sentences (1) and (2) is almost entirely due to a difference in the available top-down projection.

(1) The dog that the cat that the girl fought scolded approached the colt.

(2) The vase that the maid that the agency hired dropped broke on the floor.

In both sentences the centre-embedded grammatical construction is equally difficult to process for the human mind. The difference is that in (2) the grammatically correct noun-verb pairs are supported by common experience. World knowledge thus makes it possible to bypass a grammatical difficulty by an appropriate top-down projection.

It would be a mistake, however, to see top-down processing only in relation to world knowledge. Expectations of what belongs together and what is coming next can also be generated by knowledge about, e.g., grammatical dependencies, collocational links, the topic of discourse, or beliefs of the speaker. Top-down processing is usually based on a complex interaction between different types of knowledge.

There should be no misunderstanding about the empirical status of bottom-up and top-down. While, for analytical purposes, it is certainly necessary to distinguish between these two dimensions, this must not obscure the fact that they are indeed inseparable, very much like the two sides of a sheet of paper. The one necessarily complements the other; and human discourse-based mental modelling would clearly not be possible without the integration of the two.

Success in discourse processing also depends on other processing features such as the strategic and co-operative interaction between speakers and listeners on the basis of a common ground of knowledge and beliefs. Discourse processing is of a strategic nature in that it is intentional and goal-oriented. It is geared towards the fulfilment of discourse requirements which speakers/listeners impose on their own discourse performance and products (and on that of others). Speakers/listeners want to understand each other, and 
they want to achieve this in a correct and appropriate way. They deploy their knowledge resources in order to meet their requirements; and the type, extent and precision of processing depends on what and how much is needed and when.

But knowledge alone is not enough. As discourse-based mental modelling is an attempt to bridge the physical, psychological and cognitive gap between human beings, it requires a co-operative attitude on both sides. Speakers need to adapt their discourse perfomance to the knowledge/beliefs and processing potential they assume to be accessible to the intended listeners; and listeners, on their part, have to be open to the speakers' intentions, i.e. willing to make their cognitive resources available for the purpose of being taken on a mental modelling tour. Communication is achieved when speakers and listeners meet in a co-operative endeavour to combine forces and to compensate for each others "shortcomings."

A further prerequisite for successful discourse processing is a sufficiently rich common ground of (discourse-relevant) linguistic and non-linguistic knowledge, i.e. knowledge that is shared - and mutually assumed to be shared - by speakers and listeners. The smaller the common ground, the more restricted is the range of possible communication, or the more preparatory work needs to be done. Speakers/listeners have appropriate discourse strategies at their disposal for controlling their common ground potential, and they are able, in principle, to level out differences in a co-operative way.

\section{COMPREHENSION AND PRODUCTION IN UNMEDIATED COMMUNICATION}

In unmediated monolingual communication ( $c f$. figure 2) speakers aim at initiating and controlling the addressees' mental world modelling according to a more or less specific communicative intention. Based on their linguistic knowledge, their world knowledge, previous discourse, and their appraisal of the current discourse situation, including assumptions on the common ground world knowledge and the strategic processing potential available to the addressees, speakers produce the referential, propositional, illocutionary and perlocutionary indicators they deem appropriate for this purpose.

Speakers usually start producing utterances with only a rather general idea in mind of what they want to achieve; the linguistic indicators are uttered before the mental modelling that the discourse is intended to bring about has been definitively established. The final production of discourse1 results from a continuous stream of cognitive modelling intentions, which are constantly further refined or revised through auto-feedback from the linguistic output already produced. Intention-based "thinking ahead" production of linguistic output and output-based feedback analysis (i.e. comprehension) are thus two complementary dimensions of discourse production.

This on-line interaction between modelling intentions and auto-feedback constitutes the dynamic nature of discourse production. And it relies on the rather high degree of autonomy speakers enjoy in ordinary monolingual communication: the speakers are the ones who are actually responsible for what they produce, and who are also competent to judge, in the end, whether their output is intentionally felicitous or not.

Comprehension of discoursel follows production at a more or less long extended interval, which in direct oral communication can be extremely short. Based on appropriate top down expectations, it is even possible for listeners to anticipate what the speaker is going to say, and to respond accordingly, before the corresponding production has taken place. Because of this anticipation potential, the production and comprehension of discoursel and the subsequent production of discourse $e_{2}$ are partly overlapping processes. While still attending to discourse $e_{1}$, listeners are able to plan and even start their own production of discourse ${ }^{2}$. 
There is nothing extraordinary about this. Discourse anticipation on the basis of modelling expectations mirrors discourse production on the basis of modelling intentions. Anticipation is thus a fundamental feature of strategic discourse processing. Both the anticipation and the production of discourse are projections of mental modelling into a discourse representation.

DISCOURSE-BASED MENTAL MODELLING 11 (intended by disc 1 -speaker)

DISCOURSE $_{1}$-RELATED

LINGUISTIC KNOWLEDGE

(disc ${ }_{1}$-speaker/addressee)
DISCOURSE 1 -RELATED

DISCOURSE $_{1} \quad$ WORLD/SITUATION KNOWLEDGE

(disc ${ }_{1}$-speaker/addressee)

DisCOURSE-BASED MENTAL MODELLING 12

(achieved by disc $c_{1}$-addressee)

COMMUNICATIVE

RECIPROCATION

DISCOURSE-BASED MENTAL MODELLING ${ }_{21}$ (intended by disc ${ }_{2}$-speaker $=\operatorname{disc}_{1}$-addressee)

DISCOURSE-RELATED

LINGUISTIC KNOWLEDGE

( disc $_{2}$-speaker/addressee)
DISCOURSE-RELATED

DISCOURSE $_{2}$ WORLD/SITUATION KNOWLEDGE ( disc $_{2}$-speaker/addressee)

DISCOURSE-BASED MENTAL MODELLING 22 (achieved by disc $_{2}$-addressee $=$ disc $_{1}$-speaker)

Figure 2: Comprehension and production in monolingual communication

Relevant features of discourse production and comprehension depend on the nature of the communicative interaction between speakers and listeners. In unmediated communication, a type of reciprocate interaction - e.g., question/answer, argument/reply, statement/comment - is dominant. Thus, in summary, communicative reciprocation is mainly characterised by the following:

- listeners comprehend discourse ${ }_{1}$ with the aim of providing an answer, a reply, or a comment to it;

- in what they produce, as speakers of discourse ${ }_{2}$, they are largely autonomous in the sense of being responsible for what they say;

- despite the overlap between discourse ${ }_{1}$-comprehension and discourse -production, $^{-}$ the search for the appropriate means of expression for discourse ${ }_{2}$-production is largely unaffected by the linguistic make-up of discourse ${ }_{1}$.

These are some of the relevant and distinctive processing features to which the discourse production and comprehension strategies of speakers/listeners are optimally attuned as the result of life-long language learning and communication practice. And this is also the position from which the trainee interpreter starts. As, to a large extent, the difficulty of interpreting arises from the fact that tried and tested discourse strategics prove 
insufficient in the face of new and unfamiliar processing conditions, the adaptation of old strategies and the development of new ones turn out to be the major challenge.

\section{COMPREHENSION AND PRODUCTION IN INTERPRETING}

Interpreting crucially involves the comprehension and production of discourse; a speaker produces a stretch of source discourse and the interpreter - on the basis of this discourse and of his relevant knowledge and interests - engages in processes of mental world modelling in order to be able to "respond" with the production of a stretch of target discourse. To an even greater extent than in unmediated monolingual communication, the production of the source discourse, its comprehension, and the production of the target discourse are overlapping processes; and with appropriate strategies it is possible for the interpreter to start producing segments of target discourse before the production of the source discourse is even complete ( $c f$. figure 3 ).

But this is more or less where the similarities end. Although interpreting has its roots in unmediated monolingual communication, the two processes differ on a number of major dimensions, in particular discourse requirements, conditions for comprehension and production, strategic needs and processes.

\section{DISCOURSE-BASED MENTAL MODELLING 11} (intended by disc ${ }_{1}$-speaker)

\begin{tabular}{|c|c|c|}
\hline${ }_{1}$-RELATED & & DISCOURSE $_{1}$-RELATED \\
\hline $\begin{array}{l}\text { LINGUISTIC KNOWLEDGE } \\
\text { (interpreter \& } \\
\text { (disc }_{1} \text {-speaker/addressee) }\end{array}$ & $\begin{array}{c}\text { SOURCE } \\
\text { DISCOURSE }_{1}\end{array}$ & $\begin{array}{l}\text { WORLD/SITUATION KNOWLEDGE } \\
\text { (interpreter \& } \\
\text { disc } \text {-speaker/addressee) }\end{array}$ \\
\hline
\end{tabular}

DISCOURSE-BASED MENTAL MODELLING ${ }_{12}$ (achieved by interpreter)

Communicative MEDIATION

\section{DISCOURSE-BASED MENTAL MODELLING ${ }_{21}$ (intended by interpreter)}

DISCOURSE-RELATED LINGUISTIC KNOWLEDGE (interpreter \& (disc 2 -speaker/addressee)

\section{TARGET DISCOURSE $_{1}$ \\ DISCOURSE-RELATED WORLD/SITUATION KNOWLEDGE (interpreter \& (disc 2 -speaker/addressee)}

\section{DISCOURSE-BASED MENTAL MODELLING 22}

(achieved by disc ${ }_{2}$-addressee)

Figure 3: Comprehension and production in mediated communication (translation/ interpreting)

The specific discourse requirements interpreters impose on their own interpreting performance ${ }^{3}$ may not always be well defined, and indeed interpreters may be only partly 
aware of them; yet they are the driving force behind what interpreters strategically attempt to achieve. On a fairly global level, the interpreter's requirements mainly concern the communicative transfer from source discourse to target discourse and the linguistic (and non-linguistic) presentation of the target discourse. The relevant questions are the following:

(a) How closely does the world modelling over the target discourse correspond to that over the source discourse? What omissions, elaborations, and changes are allowed/desirable/necessary and under what conditions?

(b) Is the presentation of the target discourse adequate with regard to comprehensibility, grammatical correctness, processing complexity, stylistic adequacy, and overall performance?

It may be trivial to point this out, but interpreters will only be able to fulfil a certain requirement if they possess the relevant kind of linguistic and non-linguistic knowledge, both in the declarative and the procedural mode. In their attempt to perform the necessary preparatory task of source discourse comprehension and to produce the target discourse, in accordance with their own self-imposed requirements, interpreters rely on what they know about how this can be achieved under the specific conditions and constraints determined by a given communicative situation. All this takes place under adverse conditions, and the strategic processes are, thus, bound to be different from those active in monolingual communication.

In order to cope with the manifold difficulties inherent in interpreting, interpreters attempt to convert their knowledge into strategic action - including an ultimate emergency strategy of 'requirement reduction.' These difficulties and corresponding strategic processes can be identified with reference to the determining factors of interpreting, in particular:

- the communicative transfer relation between source and target discourse;

- the sequential organisation of source discourse comprehension and target discourse production in Consecutive Interpreting;

- the parallel organisation of source discourse comprehension and target discourse production in Simultaneous Interpreting;

- $\quad$ source discourse complexity - content and/or linguistic representation.

In the following, we will take a closer look at the specific problem potential of these factors with regard to comprehension and production processes in Consecutive and Simultaneous Interpreting, and we will discuss the strategic challenges involved.

\section{The Communicative Transfer Relation between Source and Target Discourse}

As pointed out, in monolingual discourse production a speaker's initial mental modelling intention is sufficiently vague, open and flexible to allow ample room for further elaborations and changes partly triggered by feedback from the unfolding discourse in which it eventually finds its expression. A necessary prerequisite for this is the speaker's semantic autonomy, which enables him to evaluate his own discourse output and to conclude that it complies with his original discourse intention. ${ }^{4}$

Interpreting, on the other hand, is characterised (like translating) by an inevitable lack of semantic autonomy on the part of the interpreter, which considerably exacerbates the specific processing problems involved ( $c f$. Kohn 1990b). Depending on the circumstances, interpreters may have a certain degree of discretion as to what to keep and what to leave out; but they are not at liberty to shape and develop their mental modelling in dynamic feedback interaction with the ongoing target discourse in the same way as they would be able to do as autonomous communicators.

In interpreting, target discourse production has to be based on the rather precise, elaborate and definite initial mental model controlled by the target discourse speaker, and 
the search for the appropriate linguistic means of expression therefore needs to be far more precisely targeted than in monolingual communication. Interpreters have to adapt their production strategies to these unfamiliar, even adverse conditions. They have to learn, as Nida (1976: 58) puts it (with translators in mind), "to express their own creativity through someone else's creation."

Discourse-based mental modelling is not only initiated and guided but also shaped by a given linguistic discourse representation, in particular with regard to selection and organisation. For this reason, the interpreter's mental modelling on the basis of the source discourse will always be influenced and moulded by the linguistic tools that were used to generate it. And it is this same mental modelling for which the interpreter is expected to find an appropriate target discourse representation. But the linguistic tools used for generating a specific mental model cannot be simply exchanged without consequences for the mental model itself. We should therefore not expect an equivalence relation to exist between the source and the target discourse with regard to bottom up signs. 5

More often than not mental modelling based on the source discourse is insufficient for successful target discourse production. Each language or culture has its special means and conventions of expressing certain things - or not expressing them at all. And pieces of information that are not required to be made explicit in the source discourse, and thus may not be available to the addressee/interpreter, may turn out to be of vital importance for deciding on an appropriate target discourse rendering. ${ }^{6}$ In addition, each instance of discourse makes use of the language potential in a special way in order to maximise the communicative profit. Even within one and the same language changes in linguistic discourse representation are hardly possible without concomitant changes in mental modelling, and this is even more true for changes across language boundaries. ${ }^{7}$

Compared with monolingual communication, comprehension for interpreting must proceed even more integrally, less selectively, on the basis of in-depth processing of source discourse at all levels, fully exploiting the available bottom-up and top-down potential. In order to fill mental modelling gaps, the interpreter may have to rely on elaborative inferencing, backed up by appropriate memorising strategies, which may be needed to reconstitute details of previous source discourse so that a maximum degree of continuous monitoring as to the validity of the inferred elaborations is possible. In the phase of target discourse production, the interpreter may either decide to deploy adaptation strategies, and insert modelling details following target discourse conventions; or, where source-discourse based mental modelling fails to provide sufficient specification, he may resort to strategies of neutralisation and evasion, trying to avoid committing himself to a definite position ( $c f$. Kalina 1992: 254).

Cultural differences between source and target discourse pose similar problems and may require decisions on appropriate cultural adaptations.

One major goal of an interpreter's mediation effort is to make the speaker's intentions or aims accessible and clear to the target discourse audience. If source discourse frequently refers to facts or conditions commonly known to the source discourse audience but not to members of potential target discourse audiences, the interpreter's task may go beyond purely linguistic operations; it may be appropriate or advisable to make explicit for the target discourse audience elements that were only implicit in the source discourse, or to forgo the full rendering of an element which does not even exist in the target culture and can therefore not be adequately expressed in the target language. Sometimes, changing or replacing elements of the source discourse by such elements as may serve to render the intended source discourse meaning in the target language will be the most promising strategy. 
This is a task which interpreters will not always be able to perform successfully; frequently, there are too many conditions that must be fulfilled for them to succeed in such an undertaking. Unlike other forms of interpreting - community interpreting being a case in point -, great restraint is needed in deciding which additions or changes are acceptable without running the risk of triggering reactions not entirely compatible with the speaker's intentions. Moreover, replacing a source discourse element, e.g. in enumerations, by an element more common in the target culture may deprive the target discourse audience of an important means of obtaining information and building their mental model of the source discourse culture. Therefore, for such strategies to be successful, interpreters need to have an excellent knowledge and awareness of cultural characteristics and of differences between two cultures. They have to decide on the spot whether and to what extent they are able to mediate between the two cultures. This may involve verbalisation of elements which it is unnecessary to verbalise in the source discourse culture, corresponding to a strategy of elaboration, albeit with a cultural orientation. It may also take the form of a deletion if an element verbalised in the source discourse culture is redundant or not acceptable in the target discourse culture or has not even an approximate equivalent there. It may result in restructuring certain elements of information, if this corresponds more closely to the way in which such information is usually structured in the target discourse culture. Various other strategies may therefore be regarded as cultural strategies when their orientation is mediation between cultures and their aim is to transfer as much of the source discourse culture as possible with the highest degree of comprehensibility by the target discourse audience.

\section{The Sequential Organisation of Source Discourse Comprehension and Target} Discourse Production in Consecutive Interpreting

In consecutive interpreting, discourse reception and discourse production are part of separate processing phases and can thus be clearly distinguished. During the reception phase, interpreters mainly listen to the source discourse, breaking it down into coherent chunks, and using their linguistic knowledge in interaction with their world and situation knowledge in order to carry out the kind of mental modelling which will then be the basis for target discourse production.

To be better prepared for the production phase, interpreters usually take notes during reception. Note-taking, especially of details, requires attention to be split between different phases of communication and rather different activities, namely listening and analysing source discourse and deciding upon what has to be written down, the form in which it may be retrieved most easily, and what can best be memorised. ${ }^{8}$

Notes are taken strategically, i.e. the interpreter only notes down what he/she presumes not to be able to retrieve from memory during subsequent production. In cases where the source discourse has a clear macrostructure, strong cohesive ties and an unambiguous linguistic representation, a few well-chosen notes may be sufficient as retrieval cues to reactivate a complex frame, schema or scenario; in instances of poor macrostructure and weak cohesion, however, very precise note taking will be necessary. The noting of details will also be of particular relevance in connection with such things as enumerations, figures, or names.

If coherence and logic so demand and in order to achieve a better basis for memorisation through macro-restructuring, interpreters may arrange certain source discourse chunks in a different order in their notes, or decide not to take them up at all, e.g. in cases of repetition, multiple starts, or redundancy.

In this phase of taking in and "digesting" the source discourse, the interpreter is highly dependent on the rate of source discourse production: the speed, detail and sometimes also legibility of notes made are a function of the source discourse production rate. 
There will also be a certain time-lag between source discourse production of a given element and the interpreter's noting of that element, as the interpreter will segment incoming source discourse and will not normally start noting down anything until she is reassured that she has understood what the speaker intended to say.

During the target discourse production phase, the notes made during reception will help the interpreter retrieve from memory the following ( $c f$. Kalina 1991: 104):

(a) the macro-structure of the discourse,

(b) its cohesive interconnections,

(c) information at micro-level.

All this involves retrieving the relevant cues and information units from notes and memory at the right point in time, interpreting notes in such a way that memory cues are retrieved correctly and, at the same time, monitoring one's own presentation of target discourse for linguistic appropriateness and cultural explicitness.

As the interpreter has been able to build up a mental model of what she is going to say before starting her production, the major remaining tasks are those of retrieving (and retracing) this mental model, with notes and memory interacting, and finding an appropriate linguistic representation for the target discourse.

Owing to the temporal separation of the two phases, it is easier for the interpreter to liberate herself from source discourse sounds, structures and conventions, so that production is far less likely to be affected by word-by-word rendering, interferences or blends which would also be less acceptable than under the conditions prevailing in Simultaneous Interpreting. Monitoring is also less demanding, as there is only one voice to be received, and it is therefore easier to follow one's own production and decide upon repair strategies if necessary. ${ }^{9}$

While in general the interpreter is more or less autonomous in choosing her own production rate, it is nevertheless often the case that chairperson, audience or organisers will expect the interpreted version to require less time than the original discourse, if for no other reason than the fact that some members of the audience may have been able to follow the source discourse entirely or at least to a certain degree. So the strategic decision is either to speak faster than the source discourse speaker or condense the semantic content of the discourse, thus giving a macro-version containing the most relevant points.

It should be added that, occasionally, the interpreter even has a certain influence on the length of discourse segments she will process at a time. As there is normally direct visual contact with the speaker, it may be possible to signal when the interpreter thinks she should come in. Recognising such opportunities and using them with the utmost restraint is also a strategic decision to be made by the interpreter.

The Parallel Organisation of Source Discourse Comprehension and Target Discourse Production in Simultaneous Interpreting

In Simultaneous Interpreting, only a few words of source discourse are available when the interpreter has to start planning and producing the target discourse; and as soon as she starts producing, her own production process will effect her listening capacity, with the danger of her being detracted from listening to the source discourse altogether. In addition, she has to monitor her comprehension process for logic and coherence and her target discourse production for coherence, translational adequacy and linguistic correctness.

Controlling and co-ordinating these mutually overlapping activities in such a way that undue interference is avoided is of the utmost importance and requires specific strategic efforts. Interpreters need to be able to continue mental modelling on the basis of the source discourse while at the same time processing previous modelling chunks for transfer into target discourse. They must learn to cope strategically with the challenge of what 
may be termed independent co-ordination of quasi-simultaneous source discourse comprehension and target discourse production.

In this connection it is interesting to look at the time lag (décalage) between source and target discourse ( $c f$. Lederer 1978: 326). Particularly at the very beginning of the source discourse or after a major topic shift, when top-down hypotheses are weak, interpreters may wish to wait as long as possible before starting target discourse production, in order to get as much information as they can on the basis of a special bottom-up effort. At the same time, however, they need free storing capacity for processing the continuous stream of incoming discourse and will therefore tend to produce what has been stored without unnecessary delay; the natural limitations of their retention capacities may also necessitate speedy production.

In their attempt to balance these two conflicting interests, interpreters make use of specific comprehension and production strategies. As target discourse production presupposes source-discourse based mental modelling, comprehension strategies involving "early" anticipation are of major importance in this context. Interpreters need to anticipate strategically, i.e. on the basis of far less information than would be considered sufficient in monolingual communication, using every clue they can get from pragmatic inferences to lexical collocations, syntactic structures and suprasegmental features.

Depending on a variety of factors - in particular, language pairs, grammatical structures, cultural similarities or differences as well as relevant factual and procedural knowledge - target discourse production will then rely to a considerable extent on mental modelling based on early anticipation. But as discourse and corresponding mental modelling continues, it may become necessary for the interpreter to revise her hypotheses, and whether or not such revision takes place depends on successful monitoring. ${ }^{10}$ There will be a continual matching effort between the interpreter's expectancy-based target discourse production and new incoming source discourse chunks. These are accepted by the interpreter either as being in accordance with her modelling anticipation or as unexpected new information, and as the latter will have greater consequences for her mental modelling process, they will also leave stronger traces in her memory.

Frequently, target discourse production must be started before either of the above discourse chunks are integrally available and the anticipated discourse continuation is sufficiently validated. In this situation, specific production strategies must be used which ensure maximum "step by step" control and sufficient leeway for unexpected turns. These strategies often involve surface operations: either small and comparatively independent discourse chunks are identified and processed separately, or linguistic "open gambit" forms are chosen which leave the largest possible number of options for continuation and correction. If the anticipated and produced hypothesis is contradicted by the incoming discourse, strategies of relativation or outright repair are carried out.

Retrieval of linguistic target discourse forms may be seriously hampered by the continuing presence of linguistic source discourse elements throughout target discourse production. The spontaneous and intuitive search for the appropriate means of expression is vulnerable to interference from source discourse forms at all linguistic levels of target discourse production. Such interferences, often occurring in conjunction with capacity constraints or mismanagement, may easily result in target discourse translationese (with its well-known features). The presence of linguistic source discourse elements in target discourse production is therefore a fundamental problem of (simultaneous) interpreting, even more than of translating ( $c f$. Kohn 1990b). Interpreters learn to adapt their linguistic retrieval routines to such adverse conditions. At the same time, however, they may find it helpful, in a relevant situation, to feel their way into the target discourse via approximation strategies. These may lead to a "nearest possible" solution, sometimes involving 
several steps, each closer to the intended expression than the previous one ( $c f$. Riedmuiller 1989).

Production of the target discourse will also be controlled by strategic choices concerning the overall discourse presentation, ranging from pause distribution as a function of target discourse chunks, intonational strategies such as voice emphasis to match (or to substitute) lexical/grammatical means of expression, adaptation of production rate to source discourse delivery rate and/or listener requirements, and even to perceptible indication of doubt if the source/target discourse is deemed incoherent or illogical.

However, interpreters may also find themselves in a situation where their capacity is exhausted or their competence is not in accordance with the demands made on them, i.e. a situation where their mental modelling processes are severely affected or break down altogether. This is often the case when lists of numbers or unknown names are read out, or when their preparation strategies prove insufficient for the task. They will then try to overcome the situation by means of "emergency strategies", albeit with a feeling of frustration, which may help them to find back their way into a situation where they will regain control and access to strategies yielding more acceptable results.

Quite naturally, emergency strategies tend to rely heavily on the surface structure of the source discourse. In terms of results, they are very similar to the kind of interpreting referred to as translationese. They may involve word-by-word processing or transcodage, 11 and they may neither rely on the interpreter's mental model nor help him in building it up. Production monitoring, although especially necessary in these conditions, may become insufficient or break down, so that both the danger of interference and the number of target language conventions disregarded will increase correspondingly.

These strategies, if in fact they can be regarded as such, have - and should have, for that matter - a far lower degree of automation than the other strategies used to cope with the quasi-simultaneity of source and target discourse; and although almost every interpreter may have to fall back on such ways of processing from time to time, they are not representative of strategic processing in Simultaneous Interpreting.

\section{Source Discourse Complexity - Content and/or Linguistic Representation}

Ideally, the world and situation knowledge required for successful discourse processing is shared by speaker, addressees and interpreter. However, this is hardly ever the case for speaker and addressees, and it is even more difficult to achieve for the interpreter. The source discourse is not normally intended for the interpreter as addressee, and therefore rarely takes into account her knowledge background, as related to the discourse in question. There will thus often be a gap between the knowledge available to the interpreter and the knowledge required for successful discourse processing, usually resulting in a higher degree of semantic complexity and density of the source discourse for the interpreter.

A different type of complexity is connected with the linguistic representation of a given piece of source discourse, often in connection with particular styles typical of the written mode but inappropriate for oral communication. Speakers at international conferences often read out carefully prepared manuscripts. As a consequence, they tend to use linguistic means of expression that are rather complex for oral processing and may create serious difficulties for the interpreter ( $c f$. Déjean Le Féal 1978).

Conditions such as these require appropriate strategic action. They force the interpreter to perform operations that reduce the complexity of her task, so that she can still fulfil her vital function as a mediating communicator.

In order to (re)gain control, the interpreter may resort to strategies of extending or narrowing the time lag (décalage) ( $c f$. Lederer 1981: 59), which will enable her to dedicate more effort to listening, sometimes at the expense of the other efforts. She will also 
carefully chunk the information received, rendering only those chunks which she is fairly sure she has understood correctly. In cases where she is not sure of the correct comprehension, and where her world knowledge fails to bring her any closer to reliable comprehension, her rendering may become deliberately (i.e. strategically) vague to allow as many interpretations as are necessary for the (presumably) intended (i.e. correct) one to be likely to be among them. She will generalise, i.e. build propositions of a higher macro level and delete those of a lower level, offer solutions by means of approximation or attenuation and may even substitute elements of discourse not fully understood by such elements as her mental model makes available.

In order to cope with the specific processing problems resulting from an inappropriately complex linguistic representation, the interpreter may have to resort to linguistic simplification, including sentence splitting, paraphrasing and restructuring.

Compression/condensation will be an important overall rescue strategy. Again, only those elements are rendered that are of a higher macro level; also, repetitive or redundant information is deleted, or a telegraphic style is chosen for target discourse production so as to reduce the need for monitoring, and/or, if possible and acceptable, production is presented at a faster rate.

Particularly in the case of excessively fast reading (by the "speaker") of complex and difficult source discourse, the interpreter may have to resort to equally excessive condensation and simplification. The problem is, however, that adequacy of target discourse cannot be achieved in these circumstances, and any repair or correction operations will hardly be possible. On the other hand it remains an open question, whether in this case the source discourse itself will have achieved its intended effect.

\section{EMPIRICAL ANALYSIS}

As has been shown, interpreting involves a number of complex processes which can only lead to reasonably comprehensible target discourse if they are strategically controlled. Interpreting can thus be defined as strategic discourse processing geared to the interlingual transfer of mental world modelling from a source discourse to a target discourse platform.

The strategic orientation of interpreting is all-pervasive. If a strategy that has been chosen does not lead to a satisfactory result, the interpreter may try to use others. If she decides to leave the problem unsolved, however, her chosen processing strategy has failed, but this decision to abandon the problem altogether may itself be of a strategic nature, as it prevents a total breakdown and, from a global point of view, may thus be the only way of solving the other problems ahead.

Automation of strategic processes also plays an important role, for only if routine decision processes are performed more or less automatically will the interpreter have enough capacity and attention to solve the more intricate and complex problems.

Despite the definitions of individual strategies given above and notwithstanding the attempt to group them into semantic or syntactic, world-knowledge-based or linguisticknowledge-based types of strategies, such distinctions are bound to be of a theoretical nature. In practice, strategies of very different types and levels interact to a large extent. There can be no strategically controlled production unless comprehension strategies have been successful. Anticipated elements and uttered anticipations have to be monitored for correctness; there can be no error correction or repair strategies unless monitoring has taken place; sentence splitting requires strategies to maintain cohesion; paraphrasing often entails syntactic restructuring, which again requires longer décalage, more monitoring, more memory effort, etc. Any one single strategic decision will have consequences for numerous others to be taken. 
The empirical investigation of this strategic interdependence and interaction of interpreting is anything but a straightforward and easy matter. One is confronted with oral and spontaneous linguistic products, intended for one single short moment and not to be stored or repeated as such, providing only inadequate clues as to the processes of which they are the result. The primary methodological challenge is thus to be seen in bridging this fundamental empirical gap between the product and the processing dimensions of interpreting.

There have been various attempts at transcribing the linguistic products of interpreting with the aim of investigating the underlying processes. But notwithstanding very refined methods of transcription that reflect certain characteristics of the oral nature of a given interpretation, no transcript will convey a reliable picture of the product let alone of the processes involved. Trying to identify the strategies of an individual interpreter on the basis of a transcript of interpreted discourse alone is therefore an undertaking fraught with uncertainties; in most cases it will not even be possible to decide, without additional data, whether strategic processing has taken place at all.

This methodological conflict between the goal of investigation (= process) and the data available (= product) is well-known from second-language acquisition research ( $c f$. Kohn 1990a) and also from psycholinguistic approaches to translation. In both areas, the integration of introspective data, in particular thinking-aloud protocols, resulted in a major empirical and theoretical breakthrough ( $c f$. Færch and Kasper 1987; House and Blum-Kulka 1986; Kohn 1988; Königs 1991; Krings 1986; Lörscher 1991; Séguinot 1989; Tirkkonen-Condit 1991).

In order to obtain at least some ideas about what may go on in the heads of simultaneous interpreters during their work, we adapted the introspective verbalisation method to the specific conditions of interpreting. In our investigations, interpreters were confronted with their recorded product immediately after having done a simultaneous interpretion, and were prompted to reactivate and verbalise what had gone on in their minds at particular points of their interpretation.

Results of such studies may be helpful in revealing potential explanations of certain phenomena and may lead to the establishment and investigation of more differentiated hypotheses. But this, again, can only be one component of a very comprehensive research effort, as results obtained with retrospective methods have to be analysed with great restraint.

The degree of spontaneity to be expected from such reactions is far lower than either that of translators who engage in in-process introspection or that of the simultaneous interpreter himself when at work. There is ample room for more or less conscious amending or manipulating of what has really taken place in the process, and sometimes the memory, already exhausted by the simultaneous interpreting process, fails the interpreter who simply cannot remember either what he has said or why he has taken a certain decision. Self-observation may be an additional instrument but its results are subject to the same reservations as those set out above.

Despite all these reservations, such retrospective analyses have yielded useful insights which need to be further pursued and have already given rise to some follow-up studies.

The following passage is taken from a professional three-language conference on legal co-operation (combating fraud in the EEC), which was fully recorded and transcribed; subsequently, the (professional) interpreter in question - prompted by listening to the recording - tried to verbalise as much as she could of what had taken place in her mind while doing the (simultaneous) interpretation. The transcript together with the "introspective comment" should provide further illustration of the strategic nature of the interpreting process. 
Some of the findings can be regarded as fairly reliable, others may be of a more hypothetical nature (such as anticipation, as measurement was not very precise), but the strategies identified and the effect some decisions had on other segments of text and on other strategic decisions become quite apparent.

The format of the transcript presented below was chosen with the reader in mind; fuller representation of prosodic details in the transcript would have distracted from those strategies that can be made transparent within the scope of the present study.

\section{TRANSCRIPT}

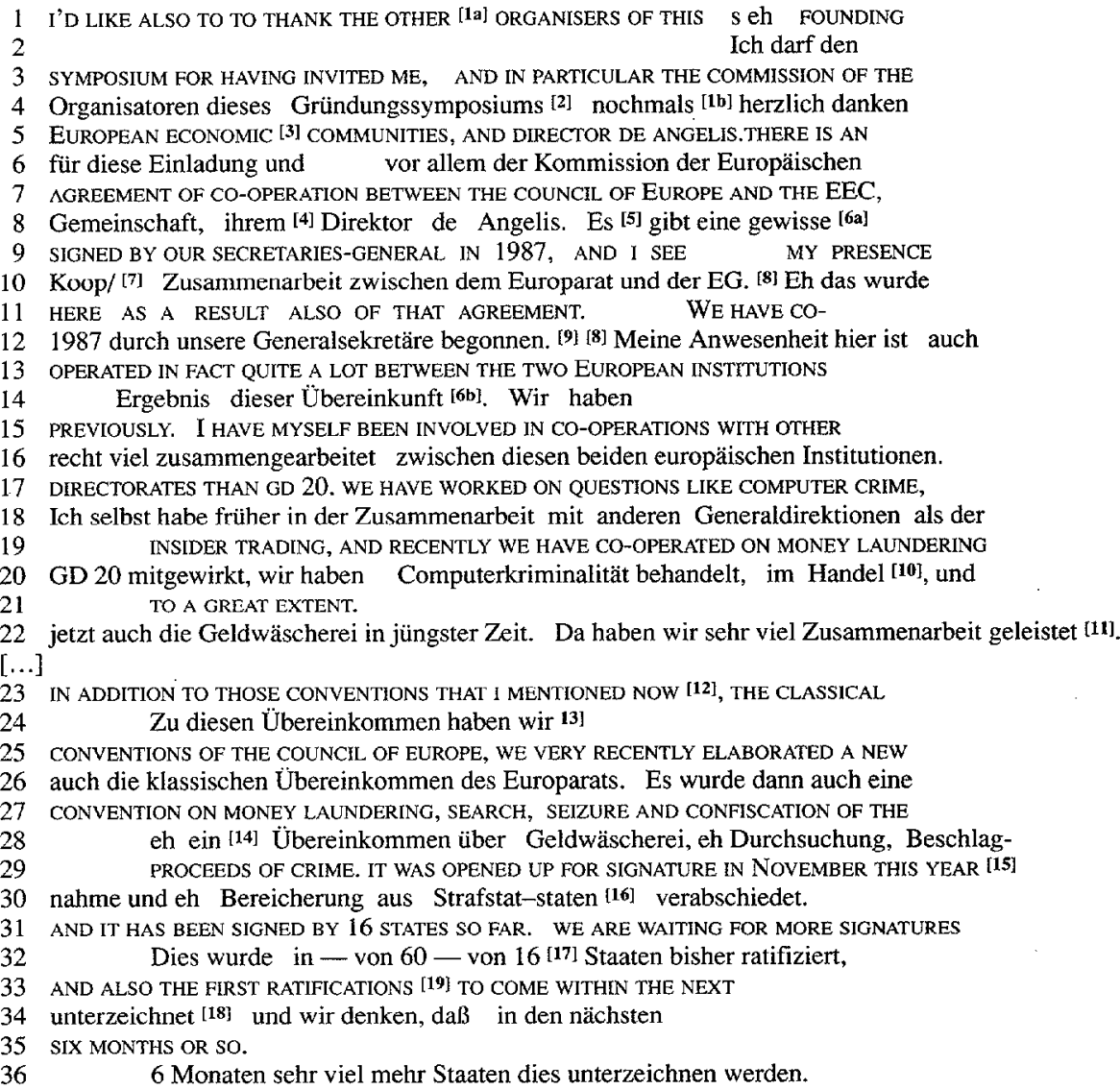

\section{COMMENTS}

(1a) Omission: source discourse presentation (by non-native speaker) sounds rather shaky, a circumstance which may have distracted the interpreter's attention and diminished her concentration; personal thanks by the speaker to his friend (the chairman) and then some factual remarks preceded this stretch of discourse where formal thanks are expressed.

(1b) Completion in order to establish cohesion with preceding target discourse as referred to in (1a).

(2) Chunking audible from pause distribution (typical in Simultaneous Interpreting); a segment has been understood, a proposition completed with the verb danken, so that the interpreter can drop this information from her memory as being processed, takes a short rest, then starts again with the next segment. 
(3) Deletion of redundant element in adaptation to target language convention: Europäische Gemeinschaft(en) and $E G$ are more common and more correct in German, whereas 'the European Economic Community(ies)' and 'EEC' are preferred in English; another reason to cut down number of words/text quantity is that décalage needs to be reduced to cope with names, figures, etc. that follow immediately.

(4) Knowledge-based explication which serves to strengthen cohesion without requiring too much processing effort.

(5) Décalage: interpreter starts production as end of segment is anticipated.

(6a) Attenuation/relativation to make up for ambiguity of 'agreement' (which can be more or less formal and would thus be rendered with different terms in German).

(6b) Subsequently added precision to correct (6a) has been possible on the basis of monitoring, as meanwhile 'secretaries general' and 'signed' have hinted at formal level of agreement.

(7) Contamination or interference: source term form is too immediately present and, as last word of a combined term, tends to remain longest in short-term-memory; monitoring leads to correction.

(8) Sentence splitting: stored information is added in separate syntactical construction to relieve memory capacity from having to store simultaneously the information chunk as such and the syntactic form in which the interpreter has started to produce it for target discourse.

(9) Substitution for verb that has gone unheard though it may well have been heard initially and served to disambiguate 'agreement,' but was then forgotten owing to effort made to processing a figure.

(10) Insufficient retrieval of world knowledge: enumeration contains unexpected element 'insider trading,' part of which is transcoded so that vague idea is preserved.

(11) Addition of phrase to find closer approximation to 'co-operated' and make up for vagueness of previous utterance (10).

(12) Deletion of redundant segment to overcome time lag and catch up with source discourse speaker, the resulting insufficient décalage leads to (13).

(13) Erroneous anticipation: on basis of linguistic structure and intonation, new element 'classical...' is expected, which turns out to be complement to the first element. This finding was revealed during a thinkaloud effort; the phenomenon occurs frequently in Simultaneous Interpreting from English into German.

(14) Continuing presence of source language form: 'convention' is rendered as Konvention with feminine article; monitoring enables new start for correct target language form by correcting article and then producing standard term.

(15) Deletion/omission due to difficulties encountered when processing previous elements: legal terms requiring exact equivalences, whose retrieval was felt to be more difficult as they are stored - and activated with special legal knowledge, not with general knowledge.

(16) Blend - correction failure: no further attempt is made, either because failure goes unrealised or because effort has to be concentrated on following problem.

(17) World-knowledge-based correction: ' 60 ' is not plausible. The think-aloud effort revealed that interpreter was uncertain about the figure, activated her world knowledge (number of EEC and Council of Europe

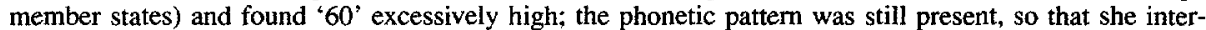
preted it as '16'. A frequent source of errors when English is source language.

(18) Approximation: verb with similar meaning is tentatively produced; during the attempt, the exact term can be retrieved.

(19) Deletion to avoid further confusion between the terms 'ratification' and 'signature' as had occurring immediately before in (18); capacity for correct processing is judged to be insufficient for carrying out the full operation.

\section{Notes}

1. Such training is of rather recent origin and its relevant methodology has only just become an object of scientific study ( $c f$. Seleskovitch and Lederer 1989; Kalina 1992).

2. The approach is restricted to propositional meaning alone; illocutionary meaning is explicitly excluded: "Mais l'interprète, lui, se situe strictement au niveau des sens. Il ne se permettra pas de traduire 1 l fait froid par Fermez la fenêtre ou Vous fumez? par Est-ce que la fumée vous dérange? Il lui faut, pour être clair, utiliser dans sa langue d'expression des formes linguistiques différentes de l'original, mais celles-ci désignent les mêmes notions, qu'on les appelle sens, idée ou réalité" (Seleskovitch 1985: 24).

3. In this context, it should be noted that in addition to the requirements interpreters impose on their own production, they also have requirements they expect the producer of the source discourse and the addressees (or recipients) of the target discourse to meet; also, they have requirements concerning the overall situation, including technical aspects.

4. A typical speaker comment would thus be: "This is exactly what I wanted to say!" - irrespective of the fact that something along the lines of "I am satisfied with what I have just said" would be far more appropriate. 
5. The traditional problem of translation equivalence seems to disappear once we adopt a mental modelling approach to interpreting/translation (cf. Kohn 1993).

6. Wienold $(1990 \mathrm{a}, \mathrm{b})$ presents a lucid linguistic analysis of translation problems resulting from typological differences between Japanese and German. The empirical material is taken from literary translations and covers lexical, morphological, syntactic and narrative structures.

7. It should be evident that the popular "language independence of meaning" hypothesis ( $c f$. Seleskovitch 1975,1978 ) cannot be upheld within the framework of a mental modelling approach.

8. For the dispute between schools about note-taking, its form and elaborateness, $c f$. Rozan 1973, Seleskovitch 1975 (1988) and Matyssek 1989.

9. It is mainly for these reasons that Consecutive Interpreting is (sometimes) considered to be less complex, easier to cope with, and therefore easier to learn than Simultaneous Interpreting ( $c f$. Seleskovitch and Lederer 1989: 126).

10. Kirchhoff's definition of Outputkontrolle (1976: 59) is narrower, referring to the functional equivalence of uttered segments (p. 67). In our approach, the concept of monitoring is adapted from second-language acquisition research covering three phases: planning, production and retrospection (cf. Kohn 1990a).

11. Lederer (1978: $327 \mathrm{ff}$.) distinguishes between different types of transcodage and describes situations where it may be a strategic operation.

\section{REFERENCES}

BROWN, G. and G. YULE (1983): Discourse Analysis, Cambridge, Cambridge University Press.

CLARK, H. H. and S. E. HAVILAND (1977): "Comprehension and the Given-new Contract", R. O. Freedle (Ed.), Discourse Production and Comprehension, Norwood (N.J.), Ablex Publishing, pp. 1-40.

DE BEAUGRANDE, R.-A. and W. U. DRESSLER (1980): Introduction to Text Linguistics, London, Longman.

DÉJEAN LE FEAL, K. (1978): Lectures et improvisations. Incidences de la forme de l'énonciation sur la traduction simultanée français-allemand, Thèse de doctorat, Université de Paris III.

FARCH, C. and G. KASPER (Eds) (1987): Introspection in Second Language Research, Clevedon, Multilingual Matters.

GERVER, D. (1975): "A Psychological Approach to Simultaneous Interpretation", Meta, 20-2, pp. 119-128.

GERVER, D. and H. W. SINAIKO (Eds) (1978): Language Interpretation and Communication, New York, Plenum Press.

GILE, D. (1991): "The Processing Capacity Issue in Conference Interpretation", Babel, 37, pp. 15-27.

GRICE, P. (1975): "Logic and Conversation", P. Cole and J. L. Morgan (Eds), Syntax and Semantics 3: Speech Acts, New York, Academic Press, pp. 41-58.

HOUSE, J. and S. BLUM-KULKA (Eds) (1986): Interlingual and Intercultural Communication, Discourse and Cognition in Translation and Second Language Acquisition Studies, Tübingen, Narr.

JACKENDOFF, R. (1983): Semantics and Cognition, Cambridge (Mass.), MIT Press.

JOHNSON-LAIRD, P. N. (1983): Mental Models. Towards a Cognitive Science of Language, Inference, and Consciousness, Cambridge, Cambridge University Press.

JOHNSON-LAIRD, P. (1981): "Comprehension as the Construction of Mental Models", The Psychological Mechanisms of Language, Philosophical Transactions of the Royal Society of London, The Royal Society and The British Academy.

KALINA, S. (1991): "Zur Rolle der Theorie in der Dolmetscherausbildung", TEXTconTEXT, 6-2/3, pp. 101-113.

KALINA, S. (1992): "Discourse Processing and Interpreting Strategies - An Approach to the Teaching of Interpreting", C. Dollerup and A. Loddegaard (Eds), Teaching Translation and Interpreting - Training, Talent and Experience, Papers from the First Language International Conference, Elsinore, Denmark, 31 May-2 June 1991, Amsterdam, Benjamins, pp. 251-257.

KALINA, S. (in press a): "Some Views on the Theory and Practice of Interpreter Training and some Practical Suggestions", M. Snell-Homby and F. Pöchhacker (Eds), Translation Studies - An Interdiscipline, Selected Papers from the Translation Studies Congress, Vienna, 9-12 Sept. 1992, Amsterdam, Benjamins, pp. 219-226.

KALINA, S. (in press b): "Analysing Interpreters' Performance - Methods and Problems", C. Dollerup and A. Lindegaard (Eds), Teaching Translation and Interpreting. Insights, Aims, Visions, Amsterdam, Benjamins.

KALINA, S. and K. KOHN (1991): "Zur Rolle der Theoric in der Dolmetscherausbildung", K. J. Mattheier (Ed.), Ein Europa - Viele Sprachen, Kongreßbeiträge zur 21 . Jahrestagung der GAL, Bern/Frankfurt a.M., Peter Lang, pp. 201-203.

KIRCHHOFF, H. (1976a): "Das dreigliedrige, zweisprachige Kommunikationssystem Dolmetschen", Le langage et l' homme, 11-2, pp. 21-27.

KIRCHOFF, H. (1976b): "Das Simultandolmetschen: Interdependenz der Variablen im DolmetschprozeB, Dolmetschmodelle und Dolmetschstrategien", H. W. Drescher and S. Scheffzek (Eds), Theorie und Praxis des Übersetzens und Dolmetschens, Bern/Frankfurt a.M., Peter Lang, pp. 59-71. 
KOHN, K. (1988): "Fachsprache und Fachübersetzen, Psycholinguistische Dimensionen der Fachsprachenforschung", C. Gnutzmann (Ed.), Fachbezogener Fremdsprachenunterricht, Tübingen, Narr, pp. 39-64.

KOHN, K. (1990a): Dimensionen lernersprachlicher Performanz. Theoretische und empirische Untersuchungen zum Zweitsprachenerwerb, Tübingen, Narr.

KOHN, K. (1990b): "Translation as Conflict", P. H. Nelde (Ed.), Confli(c)t, ABLA Papers (Association Belge de linguistique appliquée), no 14, pp. 105-113.

KOHN, K. (1993): "Contrastive Analysis and Translation", H. U. Seeber and W. Göbel (Eds), Anglistentag 1992 Stuttgart, Proceedings, vol. XIV, Tübingen, Niemeyer, pp. 327-336.

KÖNGS, F. (1991): "Dem Übersetzen den Prozeß machen? Psycholinguistische Überlegungen zum Übersetzen und ihre didaktischen Konsequenzen", E. Iwasaki (Ed.), Akten des VIII. Internationalen GermanistenKongresses Tokyo 1990, Begegnung mit dem 'Fremden', Grenzen - Traditionen - Vergleiche, Band 5, München, Iudicium Verlag, pp. 132-142.

KRINGS, H. (1986): Was in den Köpfen von Übersetzern vorgeht. Eine empirische Untersuchung zur Struktur des Übersetzungsprozesses an fortgeschrittenen Französischlernern, Tübingen, Narr.

KURZ, I. (1989): "Conference Interpreting: User Expectations", D. L. Hammond (Ed.), Coming of Age, Proceedings of the 30th Annual Conference of the AT, Medford (N.J.), Learned Information, pp. $143-148$.

KURZ, I. (1992): Simultandolmetschen als Gegenstand der interdisziplinären Forschung, Habilitationsschrift, Universität Wien.

LEDERER, M. (1978): "Simultaneous Interpretation: Units of Meaning and other Features", Gerver and Sinaiko (Eds), Language Interpretation and Communication, New York, Plenum Press, pp. 323-333.

LEDERER, M. (1980): La traduction simultanée, Fondements théoriques, Paris, Minard, Lettres Modernes.

LEDERER, M. (1981): La traduction simultanée. Expérience et théorie, Paris, Minard, Lettres Modernes.

LEDERER, M. (1985): “L'interprétation, manifestation élémentaires de la traduction”, Meta, 30-1, pp. 25-29.

LÖRSCHER, W. (1991): Translation Performance, Pranslation Process, and Translation Strategies, A Psycholinguistic Investigation, Tübingen, Narr.

MACKINTOSH, J. (1985): "The Kintsch and van Dijk Model of Discourse Comprehension and Production Applied to the Interpretation Process", Meta, 30-1, pp. 37-43.

MASSARO, D. W. (1975): Understanding Language: An Information-Processing Model of Speech Perception, Reading, and Psycholinguistics, New York, Academic Press.

MATYSSEK, H. (1989): Handbuch der Notizentechnik für Dolmetscher, Ein Weg zur sprachunabhängigen Notation, Teil 1 und Teil 2, Heidelberg, Groos.

MOSER, B. (1978): "Simultaneous Interpretation: A Hypothetical Model and its Practical Application", Gerver and Sinaiko (Eds), Language interpretation and Communication, New York, Plenum Press, pp. 353-368.

NIDA, E. (1976): "A Framework for the Analysis and Evaluation of Theories of Translation", R. W. Brislin (Ed.), Translation, Applications and Research, New York, Gardner Press, pp. 47-91.

PÖCHHACKER, F. (1991): "Einige Überlegungen zur Theorie des Simultandolmetschens", TEXTConTEXT, 6 , pp. 37-54.

PÖCHHACKER, F. (1993): Simultandolmetschen als komplexes Handeln, Ein Theorie- und Beschreibungsrahmen, dargestellt an einer Fachkonferenz, Dissertation, Geisteswissenschaftliche Fakultät der Universität Wien.

RIEDMÜLLER, Th. (1989): Strategien beim Simultandolmetschen, Mit Beispielen aus Verdolmetschungen aus dem Spanischen ins Deutsche, Diplomarbeit, Institut für Übersetzen und Dolmetschen, Universität Heidelberg.

ROZAN, J.-F. (1973): La prise de notes en interprétation consécutive, deuxième édition. Genève, George.

SEGGINOT, C. (Ed.) (1989): The Translation Process, Toronto, H. G. Publications, York University.

SELESKOVITCH, D. (1975): Langage, langues et mémoire. Étude de la prise de notes en interprétation consécutive, Paris, Minard, Cahiers Champollion, Lettres modernes.

SELESKOVITCH, D. (1976): "Interpretation: A Psychological Approach to Translating", R. Brislin (Ed.), Translation: Applications and Research, New York, Gardner Press, pp. 92-115.

SELESKOVITCH, D. (1978): "Language and Cognition", Gerver and Sinaiko (Eds), Language Interpretation and Communication, New York, Plenum Press, pp. 333-341.

SELESKOVITCH, D. (1985): "Interprétation ou interprétariat ?", Meta, 30-1, pp. 19-24.

SELESKOVITCH, D. (1988): Der Konferenzdolmetscher. Sprache und Kommunikation, TEXTconTEXT, Beiheft 2, Heidelberg, Groos (= Langage, langues et mémoire. Étude de la prise de notes en interprétation consécutive, Paris, Minard, Cahiers Champollion, Lettres Modernes, 1975).

SELESKOVITCH, D. and M. LEDERER (1989): Pédagogie raisonnée de l'interprétation, Paris, Didier Érudition, Coll. «Traductologie» 4.

STENZI, C. (1989): "From Theory to Practice and from Practice to Theory", L. Gran and J. Dodds (Eds), The Theoretical and Practical Aspects of Teaching Conference Interpretation, Proceedings of the Trieste Symposium, 1986, Undine, Campanotto, pp. 23-26. 
TIRKKONEN-CONDIT, S. (Ed.) (1991): Empirical Research in Translation and Intercultural Studies, Selected Papers of the TRANSIF Seminar, Savonlinna 1988, Tübingen, Narr.

VAN DIJK, T. A. and W. KINTSCH (1983): Strategies of Discourse Comprehension, New York, Academic Press.

WIENOLD, G. (1990a): "Typological Aspects of Translating Literary Japanese into German, I: Lexicon and Morphology", Target, 2-1, pp. 1-21.

WIENOLD, G. (1990b): "Typological Aspects of Translating Literary Japanese into German, II: Syntax and Narrative Structure", Target, 2-2, pp. 183-197. 